\title{
Phosphoglycerate mutase 1 is highly expressed in C6 glioma cells and human astrocytoma
}

\author{
ZHI-GUO LIU ${ }^{1}$, JIE DING $^{2}$, CHUAN DU $^{3}$, NING XU $^{4}$, EN-LE WANG ${ }^{5}$, \\ JIAN-YI LI ${ }^{6}$, YUN-YAN WANG ${ }^{7}$ and JIN-MING YU ${ }^{8}$ \\ ${ }^{1}$ Department of Neurosurgery, Shandong Cancer Hospital, Shandong Provincial Institute of Cancer Prevention \\ and Treatment, Shandong Provincial Hospital Affiliated to Shandong University, Jinan, Shandong 250017; \\ ${ }^{2}$ Department of Respiration Medicine, Xi'an Chest Hospital, Xi'an, Shanxi 710100; ${ }^{3}$ Department of Neurosurgery, \\ Zhangqiu People's Hospital of Shandong Province; Departments of ${ }^{4}$ Radiology and ${ }^{5}$ Chinese Acupuncture, \\ Zhangqiu People's Hospital of Shandong Province, Jinan, Shandong 250200, P.R. China; ${ }^{6}$ Department of Pathology \\ and Laboratory Medicine, North Shore University Hospital and Long Island Jewish Medical Center, Northwell Health, \\ Donald and Barbara Zucker School of Medicine at Hofstra/Northwell, Lake Success, NY 11042, USA; \\ ${ }^{7}$ Department of Neurosurgery, Qilu Hospital of Shandong University, Brain Science Research Institute of \\ Shandong University; ${ }^{8}$ Department of Oncology, Shandong Cancer Hospital, Shandong Provincial Institute of \\ Cancer Prevention and Treatment, Jinan, Shandong 250117, P.R. China
}

Received December 15, 2015; Accepted April 24, 2017

DOI: $10.3892 / \mathrm{ol} .2018 .8477$

\begin{abstract}
The aim of the present study was to examine the expression of phosphoglycerate mutase 1 (PGAM1) in astrocytomas, and to investigate its role in the progression of astrocytomas. The expression of PGAM1 mRNA in rat C6 glioma cells and normal astrocytes was determined using the reverse transcription-semi-quantitative polymerase chain reaction, and immunohistochemistry was used to detect the expression of PGAM1 protein in human astrocytomas and adjacent brain tissue. These data suggested that the expression of PGAM1 in rat C6 glioma cells was significantly increased compared with that of normal astrocytes $(\mathrm{P}<0.05)$, and the expression of PGAM1 protein in human astrocytoma tissue was significantly increased compared with that of the brain tissue surrounding the tumor $(\mathrm{P}<0.05)$. In addition, PGAM1 protein was more frequently expressed in high-grade astrocytomas compared with low-grade astrocytomas. These data indicate that the expression of PGAM1 is increased in C6 cells and human astrocytomas, and PGAM1 is probably involved in the tumorigenesis and progression of glioma, which may be a potential target for glioma treatment.
\end{abstract}

Correspondence to: Professor Jin-Ming Yu, Department of Oncology, Shandong Cancer Hospital, Shandong Provincial Institute of Cancer Prevention and Treatment, 440 Yan Ji Road, Huaiyin, Jinan, Shandong 250117, P.R. China

E-mail:1zg05211@126.com

Key words: phosphoglycerate mutase 1, glioma, astrocytoma, semi-quantitative reverse transcription polymerase chain reaction, immunohistochemistry

\section{Introduction}

Gliomas are the most common primary malignant brain tumor with poor clinical outcome and account for 40-50\% of primary intracranial neoplasms (1). The etiology and pathogenesis of gliomas remain to be elucidated. Despite the advances in therapeutic approaches, treatment offers limited aid in prolonging survival (2). In view of the overall poor outcome with current therapies, a better understanding of glioma etiology is crucial for future development of more effective treatments to cure this rapidly progressing disease.

It has been demonstrated that the growth of cancer cells is primarily dependent on the glycolysis pathway (3). Phosphoglycerate mutase 1 (PGAM1) catalyzes the conversion of 3-phosphoglycerate (3-PG) to 2-phosphoglycerate (2-PG) to release energy and is one of the key enzymes in the glycolytic pathway. A previous study by Ramanathan et al (3) suggested that knocking out the glycolysis pathway may cause extreme damage to tumor cells. However, the role of PGAM1 in glioma is poorly investigated.

In the present study, PGAM1 mRNA expression in rat C6 glioma cells and astrocytes, and the protein expression in human infiltrating astrocytomas of different World Health Organization (WHO) grades (4) and peritumoral brain tissue were investigated, and the role of PGAM1 in glioma proliferation and progression was discussed.

\section{Materials and methods}

Animals and cells. A total of 40 male adult Sprague-Dawley rats about 3 months old, weight $250 \pm 30 \mathrm{~g}$, were provided by the Experimental Animal Center of Shandong University (Jinan, China), and maintained in a climate-controlled and sound isolated room $\left(21^{\circ} \mathrm{C}\right)$ under a 12:12-h light:dark cycle, 
with 40-60\% relative humidity and fed on laboratory chow and water ad libitum. Following 1-week acclimation, rats were sacrificed by intraperitoneal injection of sodium pentobarbital (45 mg/kg). Brain tissue was obtained for the experiments. The glioma C6 cell lines were purchased from the Institute of Biochemistry and Cell Biology, Chinese Academy of Sciences (Shanghai, China). Ethical approval was provided by the Ethics Committee of Qilu Hospital (Shandong, China).

Patient specimens. A total of 102 cases of astrocytomas treated in the Department of Neurosurgery, Shandong Cancer Hospital (Jinan, China) and Qilu Hospital of Shandong University (Jinan, China) between December 2011 and June 2013 were collected (59 males and 43 females; median age, 47 years; age range, 28-66 years). According to WHO 2007 criteria, 38 cases were WHO grade II, 30 cases were WHO grade III and 34 were WHO grade IV (4). A total of 11 cases of peritumoral brain tissue were also collected. No patients had ever received chemotherapy or radiation therapy prior to surgery.

Reagents. TRIzol was purchased from Invitrogen (Thermo Fisher Scientific, Inc. Waltham, MA, USA). Chloroform, isopropanol and diethyl pyrocarbonate-treated water were purchased from Shanghai Sangon Biological Engineering Technology Services Ltd. (Shanghai, China). Ethidium bromide (EB) was purchased from Sigma-Aldrich; Merck KGaA (Darmstadt, Germany); the reverse transcription-polymerase chain reaction (RT-PCR) PrimeScript ${ }^{\mathrm{TM}}$ RT reagent kit (cat no. RR037A) was purchased from Takara Biotechnology Co., Ltd. (Dalian, China), deoxynucleotide triphosphates (dNTPs), Taq DNA polymerase and CASsuper 7Kb DNA Marker were purchased from Promega Corporation (Madison, WI, USA). Poly-L-lysine, immunohistochemical hypersensitivity kit, goat anti-human PGAM1 antibody (sc-376638), 3,3'-diaminobenzidine (DAB) dye (sc-24982) and antibody dilutions (sc-2023) were purchased from Santa Cruz Biotechnology, Inc. (Dallas, TX, USA).

Culture, passage and identification of astrocytes. Bilateral brain cortex tissue $(\sim 0.5 \mathrm{~g})$ from 1 -week-old SD rats was collected and washed with $\mathrm{Ca}^{2+} / \mathrm{Mg}^{2+}$-free Hanks solution (sc-391061; Santa Cruz Biotechnology, Inc.) twice. The brain tissue was shredded and kept at room temperature for $10 \mathrm{~min}$ with trypsin (sc-391055; 1:250; Santa Cruz Biotechnology, Inc.). The resulting brain tissue was transferred into the centrifuge tube and centrifuged at $1,000 \mathrm{x} \mathrm{g}$ for $3 \mathrm{~min}$ at $4^{\circ} \mathrm{C}$ for cell separation. Cell suspension was collected and transferred into a new tube and centrifuged at 1,500 $\mathrm{x} \mathrm{g}$ for $5 \mathrm{~min}$ at $4^{\circ} \mathrm{C}$. The second cell suspension was seeded into a culture flask that was previously coated $\left(4^{\circ} \mathrm{C}\right.$, overnight $)$ with poly-L-lysine (sc-286689; 0.1\%; Santa Cruz Biotechnology, Inc.). Cells were cultured with Dulbecco's modified Eagle's medium (DMEM)/Ham's F12 with $15 \%$ fetal bovine serum (FBS; 16250086; Thermo Fisher Scientific, Inc.) at $37^{\circ} \mathrm{C}$ in a $5 \% \mathrm{CO}_{2}$ incubator. Finally, astrocytes were identified with glial fibrillary acidic protein (GFAP; sc-33673; Santa Cruz Biotechnology, Inc.) immunofluorescence (5).

The immunostaining steps were as follows: Coverslips with their attached cells were removed from the culture medium and washed three times in phosphate buffered saline
(PBS; sc-286634; Santa Cruz Biotechnology, Inc.) before being fixed in 4\% paraformaldehyde (sc-281692; Santa Cruz Biotechnology, Inc.) for $1 \mathrm{~h}$ at room temperature. The coverslips were then washed three times in cold PBS (5 min each). Prior to staining, cells were permeabilised in PBS containing $0.01 \%$ Triton for $10 \mathrm{~min}$ at room temperature and then washed three times in cold PBS (3 min each). The coverslips were blocked with $10 \%$ normal goat serum for $1 \mathrm{~h}$ at $37^{\circ} \mathrm{C}$. Each coverslip was incubated with $20 \mu \mathrm{l}$ mouse anti-GFAP primary antibody (cat no. sc-33673; Santa Cruz Biotechnology, Inc.) 1:200 at $4^{\circ} \mathrm{C}$ overnight. Negative controls were incubated identically but without primary antibody. Coverslips were then washed three times in PBS, then incubated with a goat anti-rabbit secondary antibody conjugated to FITC (sc-2010; 1:100; Santa Cruz Biotechnology, Inc.) for $30 \mathrm{~min}$ at room temperature and washed three times in cold PBS 5 min each. Then the coverslips were incubated with $20 \mu 1$ DAPI (sc-3598; Santa Cruz Biotechnology, Inc.) for $5 \mathrm{~min}$ at room temperature in the dark. Images were captured using a confocal microscope (PerkinElmer, Inc., Waltham, MA, USA) at a wavelength of $520 \mathrm{~nm}$.

Culture of C6 glioma cells. C6 glioma cells were cultured in $\mathrm{DMEM} / \mathrm{Ham}$ 's F12 containing $15 \% \mathrm{FBS}$ at $37^{\circ} \mathrm{C}$ in a $5 \% \mathrm{CO}_{2}$ incubator. Following cells reaching exponential phase, they were subcultured into two culture flasks.

Total RNA extraction and detection of PGAM1 mRNA expression in rat astrocytes and C6 glioma cells

Extraction of total RNA from C6 and astrocytes. Once the cultured cells were confluent in the culture flasks, the culture medium was removed and cells were washed for $30 \mathrm{sec}$ with PBS twice. Total RNA was extracted using a TRIzol RNA extraction kit (Thermo Fisher Scientific, Inc.) according to the manufacturer's protocol. RNA concentration and quality were determined using a NanoDrop ND-1000 spectrophotometer $\left(\mathrm{A}_{260} / \mathrm{A}_{280}\right.$ values were 1.80-2.0; Thermo Fisher Scientific, Inc.) and gel electrophoresis.

Reverse transcription (first-strand cDNA synthesis). A total of $2 \mu \mathrm{g}$ total RNA, $2.0 \mu \mathrm{l} 10 \mu \mathrm{mol} / 1$ oligo dNTPs, $2.0 \mu \mathrm{l} 10 \mathrm{X}$ PCR buffer, $2.0 \mu 15 \mu \mathrm{mol} / 1 \mathrm{dNTPmix}, 1.0 \mu \mathrm{l}$ dNTP mixture, RNasin ${ }^{\circledR}$ Ribonuclease Inhibitor (4 U/ $\mu$ l; Invitrogen; Thermo Fisher Scientific, Inc.), and an appropriate amount of diethyl pyrocarbonate-treated water was added to a total volume of $20 \mu \mathrm{l}$, and thenplaced into a $0.5 \mathrm{ml}$ Eppendorf tube. The mixture was incubated at $37^{\circ} \mathrm{C}$ for $60 \mathrm{~min}$, and the reaction was stopped by heating at $70^{\circ} \mathrm{C}$ for $15 \mathrm{~min}$. Then, the reaction tube was transferred to ice, and $20 \mu 1$ Tris-EDTA buffer (Invitrogen; Thermo Fisher Scientific, Inc.) was added.

PCR and electrophoresis of PCR products. PCR primers were synthesized by Beyotime Institute of Biotechnology (Shanghai, China). The PGAM1 forward primer sequence was 5'-CCTCCTGTGAGAGCCTGAAG-3' (nt452-nt471) and the PGAM1 reverse primer sequence was 5'-CTTCTTCACCTT GCCCTGAG-3' (nt762-nt743). $\beta$-actin was used as an internal reference. A total of $2 \mu \mathrm{l} \mathrm{cDNA}, 2.5 \mu \mathrm{l} 10 \mathrm{X}$ PCR buffer, $1.5 \mu \mathrm{l} \mathrm{MgCl}_{2}, 1.0 \mu \mathrm{ldNTP}$ mixture $(2 \mathrm{mmol} / \mathrm{l}), 0.5 \mu \mathrm{l}$ forward primer $(10 \mu \mathrm{mol} / \mathrm{l}), 0.5 \mu \mathrm{l}$ reverse primer $(10 \mu \mathrm{mol} / \mathrm{l}), 0.5 \mu \mathrm{l}$ 
Taq enzyme (2 U/ $\mu \mathrm{l})$ and $16.5 \mu \mathrm{l}$ double-distilled water were added into a $0.2 \mathrm{ml}$ Eppendorf PCR tube on ice. Following PCR (pre-denaturation at $94^{\circ} \mathrm{C}$ for $7 \mathrm{~min}$, denaturation at $94^{\circ} \mathrm{C}$ for $30 \mathrm{sec}$, annealing at $56^{\circ} \mathrm{C}$ for $30 \mathrm{sec}$, extension at $72^{\circ} \mathrm{C}$ for $30 \mathrm{sec}$ ), $5 \mu \mathrm{l}$ PCR product was analyzed on $1.5 \%$ agarose gel electrophoresis at $100 \mathrm{~V}$ for $15 \mathrm{~min}$. The image was captured under UV light (WFH-204A; JK Technology, Shanghai, China). The intensity of these bands was semi-quantified using an imaging analyzer (ImageJ version 1.48; National Institutes of Health, Bethesda, MD, USA).

Immunohistochemistry on paraffin-embeddedtissue sections. Sections of paraffin tissue $5-\mu \mathrm{m}$ thick were deparaffinized by using xylene and rehydrated through a graded alcohol series to water. The dewaxed slides underwent antigen retrieval in citrate buffer (Beyotime Institute of Biotechnology, Shanghai, China) for $30 \mathrm{~min}$ by microwaving (Midea, Guangdong, China) and then cooled to room temperature. Peroxidase blocking solution (Beyotime Institute of Biotechnology, Shanghai, China) was used to block endogenous peroxidase activity at room temperature for $10 \mathrm{~min}$. Tissue sections were incubated with anti-PGAM1 antibody (1:100 dilution) at $4^{\circ} \mathrm{C}$ overnight, and then incubated with biotinylated rabbit anti-Goat antibody $(1: 1,000$; cat no. sc-2768; Santa Cruz Biotechnology, Inc.) at room temperature for $10 \mathrm{~min}$. A drop of streptavidin-biotin-peroxidase solution Beyotime Institute of Biotechnology, Shanghai, China was added onto each section and incubated at room temperature for $10 \mathrm{~min}$. Tissue sections were incubated with freshly prepared DAB chromogenic reagent for 1-2 min at room temperature, then counterstained with hematoxylin $(1 \mu \mathrm{M}$; Beyotime Institute of Biotechnology, Shanghai, China) for $3 \mathrm{~min}$ at room temperature. Ten low power fields (magnification, x100) were selected randomly and immunostaining was detected at a high power (magnification, $\mathrm{x} 400$ ) using a light microscope (BX43; Olympus Corporation, Tokyo, Japan). The immunohistochemical stain results were divided into negative $(<10 \%$ of cells with marked cytoplasmic staining), positive (10-70\% cells with marked cytoplasmic staining) and strongly positive ( $>70 \%$ cells with marked cytoplasmic staining). Positive and strongly positive results were statistically counted as positive.

Statistical analysis. Data are expressed as mean \pm standard deviation. Statistical analysis was performed using SPSS software version 14.0 (SPSS, Inc., Chicago, IL, USA). The relative absorbance of the astrocytes and C6 glioma cells was analyzed by unpaired Student's t-test. For the positive expression rates of PGAM1 in astrocytoma tissues and peritumoral brain tissue, the $\chi^{2}$ test was used, and $\mathrm{P}<0.05$ was considered to indicate a statistically significant difference.

\section{Results}

Expression of PGAM1 mRNA in C6 glioma cells and normal astrocytes. The RT-PCR PGAM1 products from astrocytes and C6 glioma were visualized by gel electrophoresis and the intensity of these bands was semi-quantified (Fig. 1A and B). Using SPSS version 14.0 statistical software, 2 samples in triplicate (C6 glioma cells vs. normal astrocytes) were compared.
Table I. Comparison of phosphoglycerate mutase 1 expression in C6 glioma cells and astrocytes.

\begin{tabular}{lcc}
\hline Group & No. of cases & $\begin{array}{c}\text { Expression quantity } \\
(\text { mean } \pm \text { SD) }\end{array}$ \\
\hline C6 glioma cells & 30 & $1.26 \pm 0.05$ \\
Astrocytes & 10 & $0.75 \pm 0.07$ \\
\hline
\end{tabular}

$\mathrm{t}=3.89, \mathrm{P}<0.05 . \mathrm{SD}$, standard deviation.

Table II. Comparison of phosphoglycerate mutase 1 protein in glioma tissue and peritumoral brain tissue.

\begin{tabular}{lcccc}
\hline Group & $\begin{array}{c}\text { No. of } \\
\text { cases }\end{array}$ & Negative & Positive & $\begin{array}{r}\text { Positive } \\
\text { rate }(\%)\end{array}$ \\
\hline Normal brain tissue & 11 & 8 & 3 & 27.2 \\
Glioma tissue & 102 & 30 & 72 & 70.6 \\
\hline
\end{tabular}

$\chi^{2}=8.35, \mathrm{P}<0.01$.

Table III. Association between phosphoglycerate mutase 1 expression and the grades of gliomas.

\begin{tabular}{lcccc}
\hline Group & $\begin{array}{c}\text { No. of } \\
\text { cases }\end{array}$ & Negative & Positive & $\begin{array}{c}\text { Positive } \\
\text { rate (\%) }\end{array}$ \\
\hline Grade II & 38 & 20 & 18 & 47.4 \\
Grade III-IV & 64 & 10 & 54 & 84.4 \\
\hline
\end{tabular}

$\chi^{2}=15.73, \mathrm{P}<0.01$.

It was identified that the expression of PGAM1 in C6 glioma cells $(1.26 \pm 0.05)$ was significantly increased compared with that of normal astrocytes $(0.75 \pm 0.07)$. The difference was statistically significant $(\mathrm{P}<0.05$; Table I).

PGAM1 immunohistochemistry of astrocytoma and peritumoral brain tissue. A total of 8/11 (73.8\%) peritumoral brain tissues were negative for PGAM1 (Fig. 2A and B). Only 3 peritumoral brain tissues were positive for PGAM1 (3/11; 27.2\%). In 102 cases of astrocytoma tissues, 74 cases (70.6\%) were positive for PGAM1 and 28 cases were negative for PGAM1. There was a statistically significant difference in PGAM1 positive rates between the astrocytoma group and the peritumoral brain tissue group $\left(\chi^{2}=8.35 ; \mathrm{P}<0.01\right.$; Table II $)$. The expression of PGAM1 in the low-grade diffuse astrocytomas (WHO Grade II; Fig. 2C and D) and high-grade astrocytomas (WHO Grade III-IV; Fig. 3) was compared. PGAM1 was predominantly confined to the cytoplasm of tumor cells (Figs. 2 and 3). The results demonstrated that $18 / 38(47.4 \%)$ cases of WHO Grade II astrocytoma were positive for PGAM1. A total of 54/64 cases $(84.4 \%)$ of high-grade astrocytomas were positive for PGAM1. The PGAM1 positive rate was significantly different between 

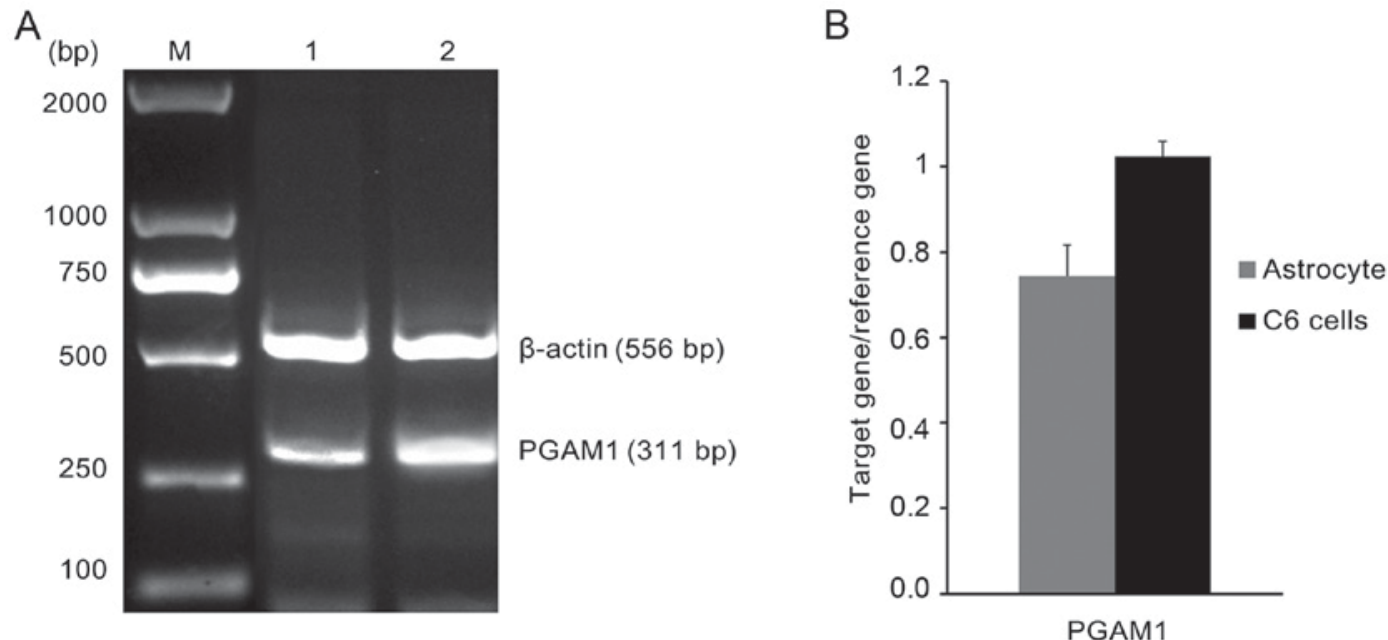

Figure 1. PGAM1 mRNA expression level in C6 glioma cells and normal astrocytes. (A) Electrophoresis of PCR products of PGAM1. M, Marker; 1, Astrocytes; 2, C6 glioma cells. (B) Semi-quantitative analysis of PCR products of PGAM1 in C6 glioma cells and normal astrocytes. PGAM1, phosphoglycerate mutase 1; PCR, polymerase chain reaction.

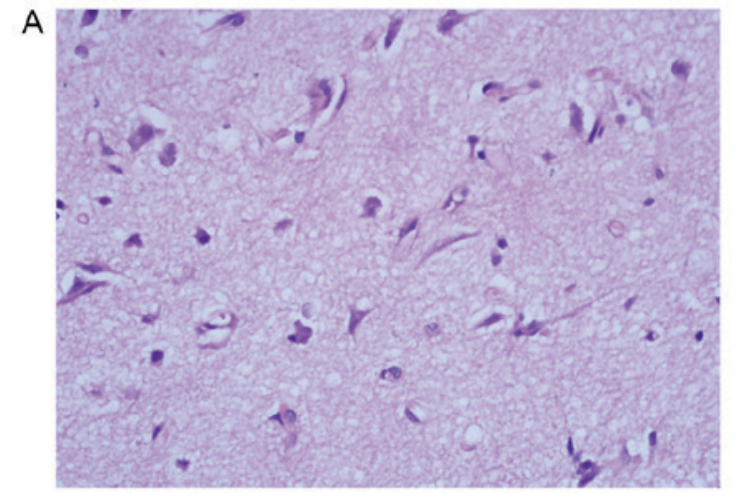

B
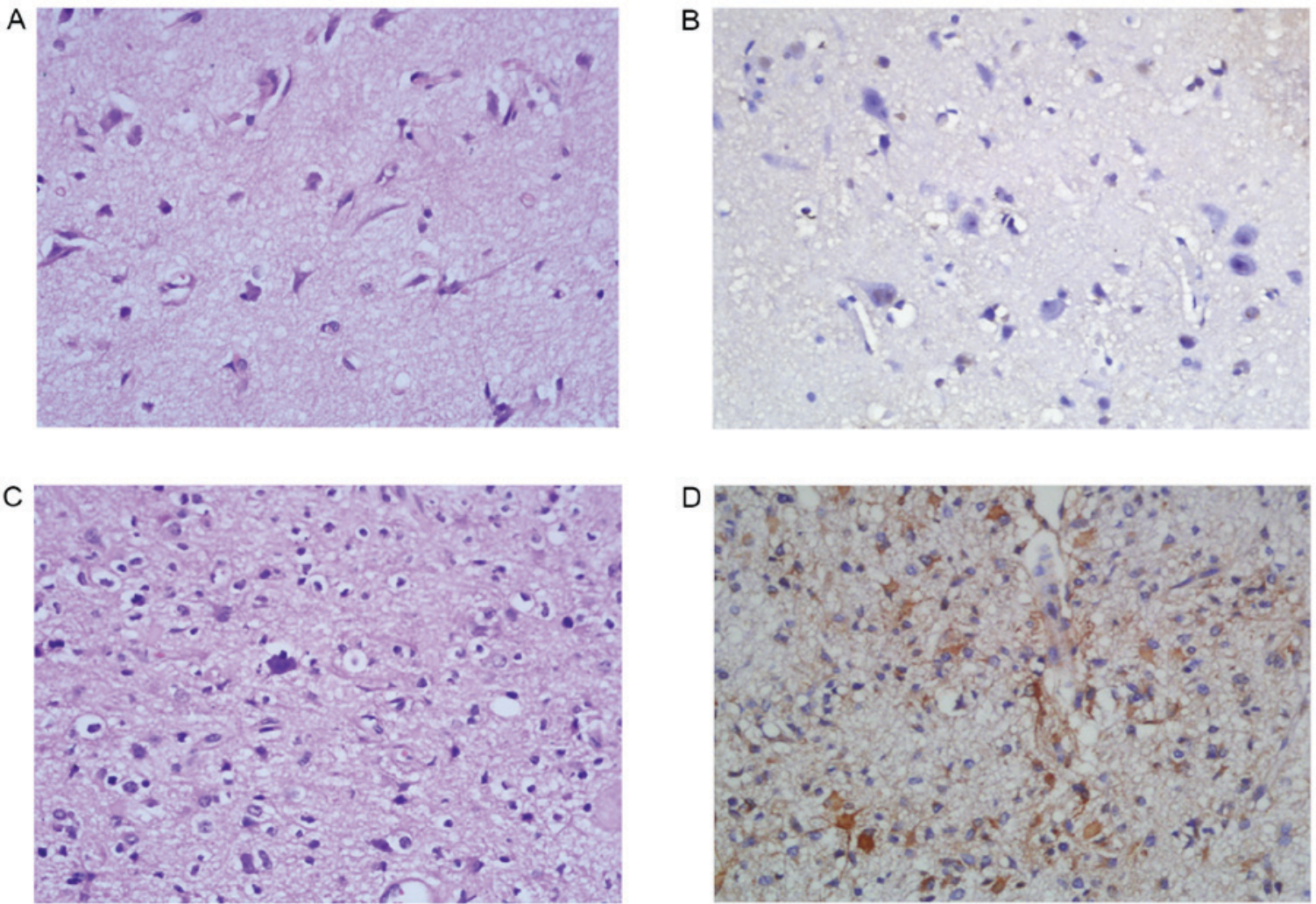

Figure 2. PGAM1 immunohistochemical staining in peritumoral brain tissue and diffuse astrocytoma (WHO grade II). (A) Hematoxylin and eosin stain of peritumoral brain tissue. Magnification, x400. (B) Peritumoral brain tissue is negative for PGAM1. Magnification, x400. (C) Hematoxylin and eosin stain demonstrates brain tissue infiltrated by mildly hypercellular glial cells with irregular and atypical nuclei and inconspicuous mitotic activity, diagnostic of diffuse astrocytoma (WHO grade II). Magnification, x200. (D) Diffuse astrocytoma is positive for PGAM1 with a cytoplasmic staining pattern. Magnification, x200. PGAM1, phosphoglycerate mutase 1 .

low-grade astrocytomas (WHO grade II) and high-grade astrocytomas (WHO grade III-IV) $\left(\chi^{2}=15.73 ; \mathrm{P}<0.01\right.$; Table III).

\section{Discussion}

As one of the key enzymes in the glycolytic pathway, PGAM1 primarily catalyzes the conversion of 3-phosphoglycerate into 2-phosphoglycerate. PGAM1 may be in muscle-derived form (m-type) and brain-derived form (b-type) in mammals (6). B-type PGAM1 has been identified previously (7). Tumor cells are distinct from normal cells by their unique feature of the glucose metabolism: Tumor cells obtain energy primarily through the glycolysis pathway, whereas normal cells primarily metabolize glucose through aerobic oxidation (8). 

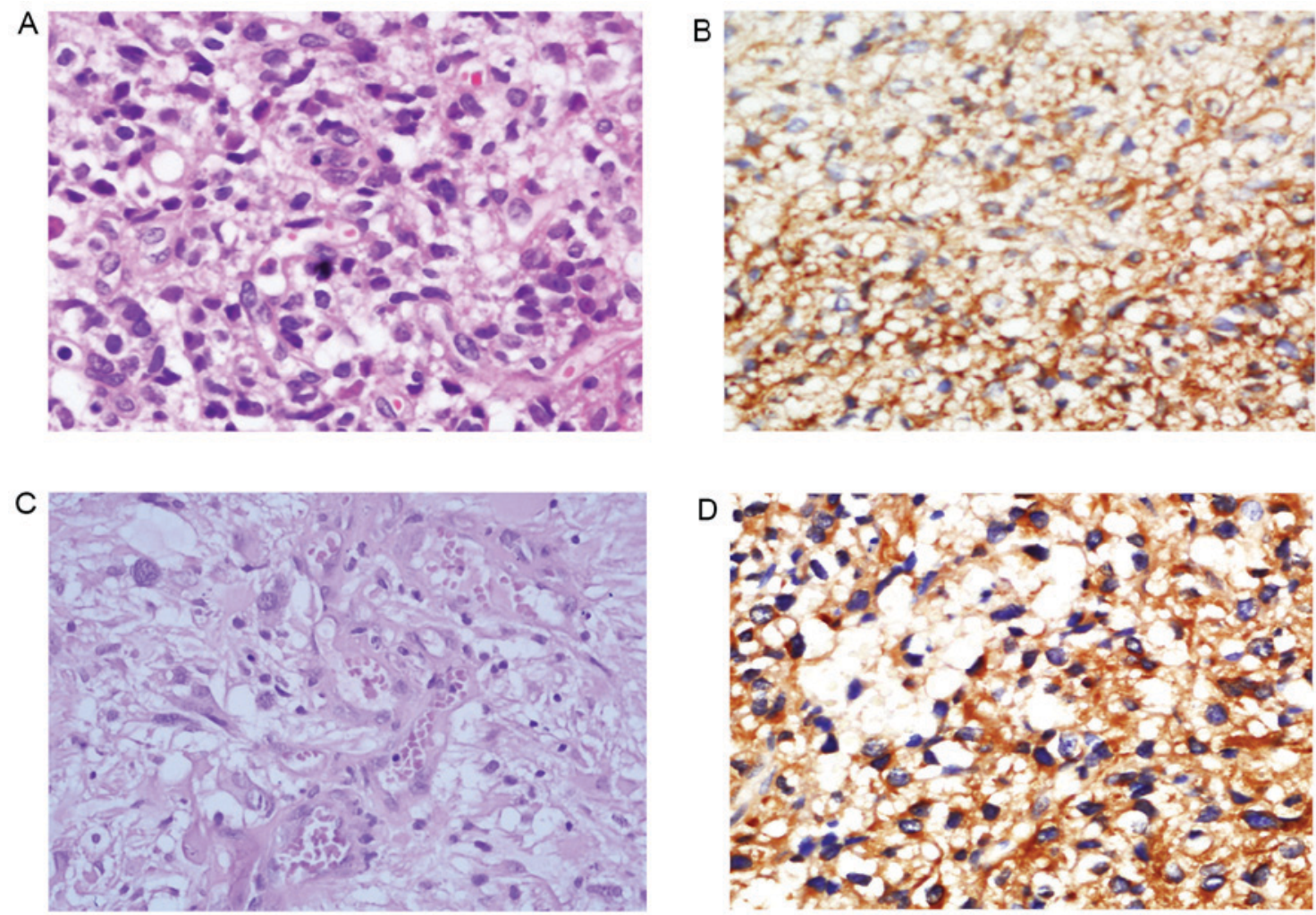

Figure 3. PGAM1 immunohistochemical stains in high-grade astrocytoma. (A) Hematoxylin and eosin stain demonstrates hypercellular astrocytoma with occasional mitoses, diagnostic of anaplastic astrocytoma (WHO grade III). Magnification, $\mathrm{x} 400$. (B) Anaplastic astrocytoma is positive for PGAM with a marked cytoplasmic staining pattern. Magnification, x200. (C) Hematoxylin and eosin staining demonstrated high-grade astrocytoma with microvascular proliferation, diagnostic of glioblastoma (WHO grade IV). Magnification, x400. (D) Glioblastoma is strongly and diffusely positive for PGAM1. Magnification, x200. PGAM1, phosphoglycerate mutase 1 .

Bustamante et al (9) identify that the hexokinase activity is markedly low in normal tissue, whereas the activity of this enzyme in tumor cells is significantly increased. Previous studies have indicated that certain enzymes which inhibit glycolysis may effectively kill liver cancer cells and other cancer cells (10-12).

PGAM1 is the only enzyme in the glycolytic pathway that is regulated at the transcriptional level by the tumor suppressor gene p53 (13), In 2005, Evans et al (14) suggest that PGAM1 may be a novel target for cancer treatment. PGAM1 is significantly upregulated in $66.7 \%$ of hepatocellular carcinomas, and markedly associated with the poorer survival of patients and poor differentiation of cancer cells (15). PGAM1 protein is overexpressed in breast cancer and prostate cancer $(16,17)$. The expression of PGAM1 is upregulated in esophageal cancer (18) and glioma cells $(19,20)$. In the present study, PGAM1 is expressed in astrocytes and C6 glioma cells using RT-semi-quantitative PCR, but that the expression level in C6 glioma cells is significantly increased compared with that of astrocytes. Using immunohistochemical staining, it is identified that the level of PGAM1 protein in astrocytoma tissue is significantly increased compared with that in peritumoral brain tissue. Furthermore, high-grade astrocytomas exhibit higher levels of PGAM1 positivity compared with low-grade astrocytomas. Therefore, PGAM1 may play an important role in the tumorigenesis and progression of malignant gliomas. The results indicate that PGAM1 inhibitors may be potential anticancer drugs, but extensive future studies are required.

In summary, the expression of PGAM1 is upregulated in glioma cell lines and astrocytoma tissues. This suggests that PGAM1 may be involved in the tumorigenesis and progression of malignant gliomas. PGAM1 may become a novel target for glioma treatment in the future.

\section{Acknowledgements}

The authors would like to thank Mr. Kuan Zhen (Department of Neurosurgery, Second Hospital of Shandong University), Mr. Yan Song (Department of Neurosurgery, Qilu Hospital of Shandong University, Brain Science Research Institute of Shandong University) and Mr. Baibin Bi (Department of Neurosurgery, Qilu Hospital of Shandong University, Brain Science Research Institute of Shandong University) for administrative and operational support.

\section{Funding}

The present study was supported by intradepartmental funding.

\section{Availability of data and materials}

All data generated during the present study are available from the corresponding author upon reasonable request. 


\section{Authors' contributions}

ZGL, JD and CD conducted the immunohistochemistry and immunofluorescence experiments. ZGL drafted the manuscript. NX, ELW and YYW participated in PCR experiments. YYW proofread the manuscript. ZGL and JD participated in data analysis, and statistical analysis. JYL made contributions to analysis and interpretation of data for histopathology and immunostain results, made the pathology figures and proofread the manuscript. JMY participated in experimental design and coordination of the study. All authors read and approved the final manuscript.

\section{Ethics approval and consent to participate}

Ethical approval was provided by the Ethics Committee of Qilu Hospital (Shandong, China).

\section{Consent for publication}

Not applicable.

\section{Competing interests}

The authors declare that they have no competing interests.

\section{References}

1. Zhou L, Editor in chief: Modern Neurosurgery. Shanghai, Fudan University Press. Front Page: 376-377, 2004.

2. Ma LN, Song B and Cai JY: Research of the killing effects of cinobufacini on MCF-7cells. Chin Pharmacol Bull 27: 37-40, 2011 (In Chinese).

3. Ramanathan A, Wang C and Schreiber SL: Perturbational profiling of a cell-line model of tumorigenesis by using metabolic measurements. Proc Natl Acad Sci USA 102: 5992-5997, 2005.

4. Louis DN, Ohgaki H, Wiestler OD, Cavenee WK, Burger PC, Jouvet A, Scheithauer BW and Kleihues P: The 2007 WHO classification of tumours of the central nervous system. Acta Neuropathol 114: 97-109, 2007.

5. Schildge S, Bohrer C, Beck K and Schachtrup C: Isolation and culture of mouse cortical astrocytes. J Vis Exp 19: pii: 50079, 2013.

6. Grisolia S and Cleland WW: Influence of salt, substrate, and cofactor concentrations on the kinetic and mechanistic behavior of phosphoglycerate mutase. Biochemistry 7: 1115-1121, 1968.

7. Scatena R, Bottoi P, Pontoglio A, Mastrototaro L and Giardina B Glycolytic enzyme inhibitors in cancer treatment. Expert Opin Investig Drugs 17: 1533-1545, 2008.
8. Jones RG and Thompson CB: Tumor suppressors and cell metabolism: A recipe for cancer growth. Genes Dev 23: 537-548, 2009.

9. Bustamante E, Morris HP and Pedersen PL: Energy metabolism of tumor cell. Requirement for a form of hexokinase with a propensity for mitochondrial binding. J Biol Chem 256: 8699-8704, 1981.

10. Ko YH, Pedersen PL and Geschwind JF: Glucose catabolism in the rabbit VX2 tumor model for liver cancer: Characterization and targeting hexokinase. Cancer Lett 173: 83-91, 2001.

11. Xu RH, Pelicano H, Zhou Y, Carew JS, Feng L, Bhalla KN, Keating MJ and Huang P: Inhibition of glycolysis in cancer cells: A novel strategy to overcome drug resistance associated with mitochondrial respiratory defect and hypoxia. Cancer Res 65: 613-621, 2005

12. Gwak GY, Yoon JH, Kim KM, Lee HS, Chung JW and Gores GJ: Hypoxia stimulates proliferation of human hepatoma cells through the induction of hexokinase II expression. J Hepatol 42: 358-364, 2005.

13. Cheung EC and Vousden KH: The role of p53 in glucose metabolism. Curr Opin Cell Biol 22: 186-191, 2010.

14. Evans MJ, Saghatelian A, Sorensen EJ and Cravatt BF: Target discovery in small molecule cell-based screens by in situ proteome reactivity profiling. Nat Biotechnol 23: 1303-1307, 2005.

15. Ren F, Wu H, Lei Y, Zhang H, Liu R, Zhao Y, Chen X, Zeng D, Tong A, Chen L, et al: Quantitative proteomics identification of phosphoglycerate mutase 1 as a novel therapeutic target in hepatocellular carcinoma. Mol Cancer 9: 81, 2010.

16. Cortesi L, Barchetti A, De Matteis E, Rossi E, Della Casa L, Marcheselli L, Tazzioli G, Lazzaretti MG, Ficarra G, Federico M and Iannone A: Identification of protein clusters predictive of response to chemotherapy in breast cancer patients. J Proteome Res 8: 4916-4933, 2009.

17. Zhang XB, Tang ZY, Zu XB, Qi L and Ruan JD: Modified serum-guided immunoblotting for differential study of prostate cancer. Zhonghua Nan Ke Xu 16: 438-444, 2010 (In Chinese).

18. Saeki H, Kitao H, Yoshinaga K, Nakanoko T, Kubo N, Kakeji Y, Morita M and Maehara Y: Copy-neutral loss of heterozygosity at the 553 locus in carcinogenesis of esophageal squamous cell carcinomas associated with p53 mutations. Clin Cancer Res 17: 1731-1740, 2011.

19. Gao H, Yu B, Yan Y, Shen J, Zhao S, Zhu J, Qin W and Gao Y: Correlation of expression levels of ANXA2, PGAM1, and CALR with glioma grade and prognosis. J Neurosurg 118: 846-853, 2013.

20. Jain R, Kulkarni P, Dhali S, Rapole S and Srivastava S: Quantitative proteomic analysis of global effect of LLL12 on U87 cell's proteome: An insight into the molecular mechanism of LLL12. J Proteomics 113: 127-142, 2015.

(c) (1) () This work is licensed under a Creative Commons

c) Attribution-NonCommercial-NoDerivatives 4.0 International (CC BY-NC-ND 4.0) License. 